\title{
Dysphagia caused by a left atrial myxoma
}

\author{
Hideki Mishima, MD, Susumu Ishikawa, MD, Yasushi Katayama, MD, and Hiroki Matsunaga, MD
}

Primary cardiac neoplasms are uncommon. Within this rare group, however, left atrial myxoma is the most common entity. We report the unusual case of a woman with left atrial myxoma with the previously unreported presentation of dysphagia and vomiting without cardiac symptoms.

\section{CLINICAL SUMMARY}

A 56-year-old woman came to our emergency department for reported repetitive dysphagia and vomiting. In the clinical findings on admission, there were no abnormal signs in the mouth, tongue, or pharynx, and chest heart sounds were normal. The jugular vein was not dilated, and edema of the lower extremities was absent. Blood examination showed slight increases in the erythrocyte sedimentation rate $(47 \mathrm{~mm} / \mathrm{h})$ and C-reactive protein level $(0.75 \mathrm{mg} / \mathrm{dL})$. There were no symptoms of heart failure on the chest radiographic findings, and the cardiothoracic ratio was $46 \%$. Electrocardiography showed left atrial load with sinus rhythm. Computed tomography showed a large neoplastic lesion $(40 \times 45 \mathrm{~mm}$ in diameter $)$ in the left atrium, occupying almost the entire left atrial space. In this case, the esophagus was mechanically compressed and displaced by the tumor (Figure 1).

Echocardiography revealed a large, slightly heterogeneous tumor with a pedicle on the atrial septum. The left atrial diameter was $44 \mathrm{~mm}$, and mitral valve deformity was not detected. The left ventricular ejection fraction was $64 \%$. Contrast esophagography showed a strong compression in the front wall of the esophagus from outside (Figure 2, A). Preoperative left atriography revealed a translucent image of the tumor, which occupied most of the inner space of the left atrium, and 2 tumor-feeding arteries from the left coronary artery were detected. Through a gastrointestinal scope, extramural compression at the level of $28 \mathrm{~cm}$ from the incisor cleft was observed without mucosal changes.

A diagnosis of left atrial myxoma was made, and tumor resection was performed through a median sternotomy. Cardiopulmonary bypass was used, with ascending aortic

\footnotetext{
From the Department of Thoracic and Cardiovascular Surgery, Tokyo Metropolitan Bokutoh Hospital, Tokyo, Japan.

Disclosures: Authors have nothing to disclose with regard to commercial support.

Received for publication July 17, 2013; accepted for publication July 26, 2013; available ahead of print Sept 9, 2013.

Address for reprints: Hideki Mishima, MD, Department of Thoracic and Cardiovascular Surgery, Tokyo Metropolitan Bokutoh Hospital, Tokyo, Japan, 4-23-15 Kotohbashi, Sumida-ku, Tokyo, Japan (E-mail: hmishima-ths@umin.ac.jp). J Thorac Cardiovasc Surg 2014;147:1417-8 $0022-5223 / \$ 36.00$

Copyright (c) 2014 by The American Association for Thoracic Surgery http://dx.doi.org/10.1016/j.jtcvs.2013.07.061
}

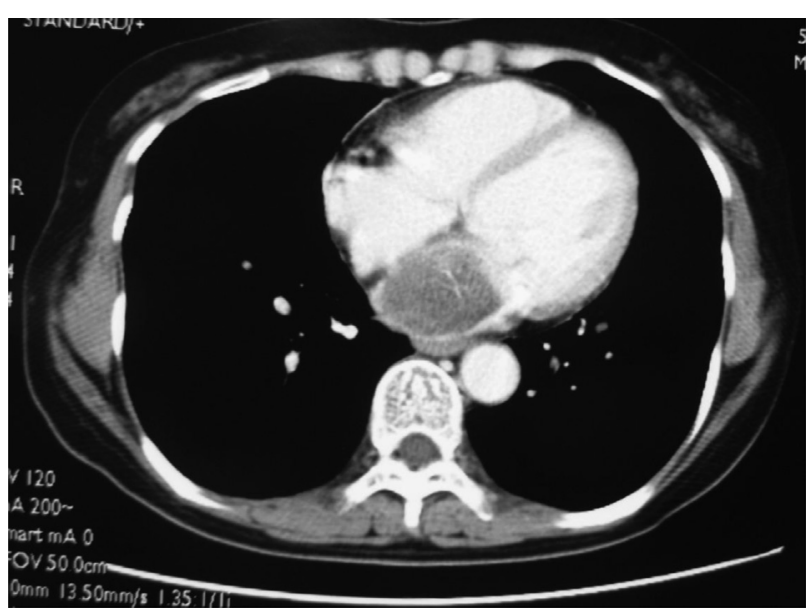

FIGURE 1. Preoperative computed tomographic image. A large neoplastic lesion $(40 \times 45 \mathrm{~mm}$ in diameter) was observed in the left atrium. The esophagus was mechanically compressed and displaced by the tumor.

and bicaval cannulation. The right atrium was opened, and we confirmed by intraoperative echocardiography that the tumor had attached to the atrial septum. After the incision of the atrial septum at the outer edge of the tumor, an oval tumor with a smooth surface was observed. It was attached to the interatrial septum broadly, without mobility. The tumor was removed with the attached septal wall, and patch closure with autologous pericardium was performed. The tumor weight was $46 \mathrm{~g}$. The postoperative pathologic diagnosis was left atrial myxoma in spindle tumor with mucus production. Dysphagia resolved after the operation.

An esophagogram revealed that the mechanical compression on the esophageal wall was no longer present (Figure 2, B). The patient was discharged on postoperative day 16. At this writing, 7 years after surgery, there have been no recurrences of myxoma or dysphagia.

\section{DISCUSSION}

The incidence of primary cardiac neoplasms ranges between $0.17 \%$ and $0.19 \%$ in unselected autopsy series. Approximately $75 \%$ of primary cardiac tumors are benign. Approximately $50 \%$ of these benign tumors are myxomas. Myxomas occur sporadically and tend to be more common in women than in men. Approximately $75 \%$ occur in the left atrium, and $94 \%$ of these tumors are solitary. ${ }^{1,2}$

General clinical presentation of left atrial myxoma involves an intracardiac obstruction with congestive heart failure $(67 \%)$, signs of embolization $(29 \%)$, systemic and constitutional symptoms of fever $(19 \%)$, weight loss or fatigue $(17 \%)$, and immunologic manifestations of myalgia, weakness, and arthralgia $(5 \%))^{3}$ A myxoma in 

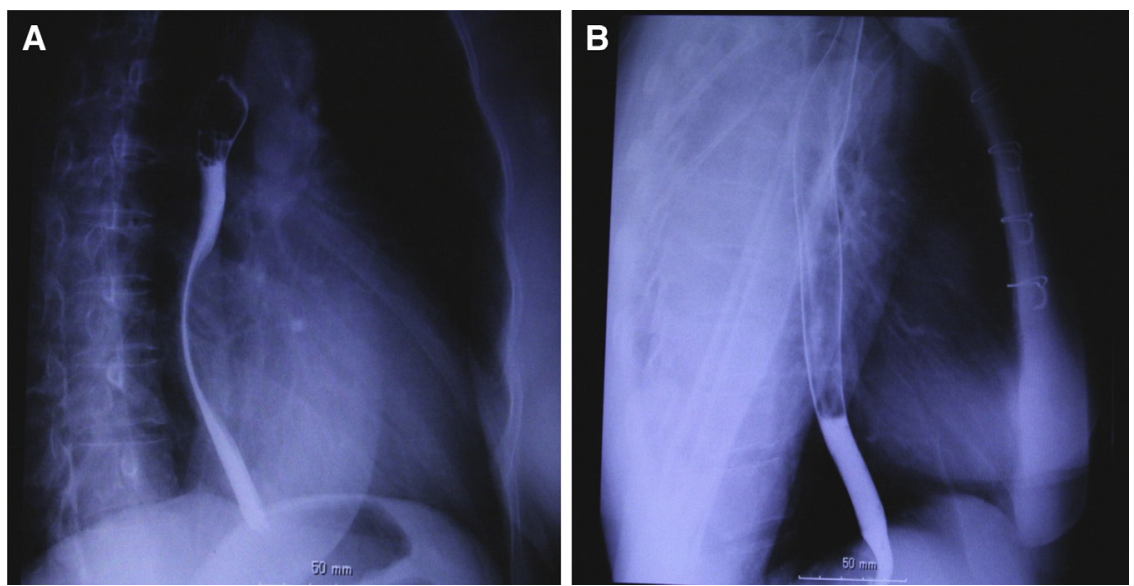

FIGURE 2. A, Preoperative contrast esophagographic image. Contrast esophagography showed a compression on the front wall of the esophagus, caused by the extramural tumor. B, Postoperative contrast esophagographic image. The mechanical compression of the extramural esophagus disappeared after surgery.

the left atrium tends to mimic mitral valvular heart disease and may produce auscultatory findings similar to mitral stenosis or regurgitation, also generating dyspnea, a symptom of arrhythmia associated with heart failure. In our case, however, heart failure was not present, and the heart sounds were normal.

Diseases that cause dysphagia in oral cavity stenotic disease in the esophagus are legion, including diseases with symptoms of esophageal extramural retraction as a result of mediastinal tumors and thoracic aortic aneurysm. Marked left atrial dilatation has been reported as an unusual cause of dysphagia. In this case, however, the left atrial diameter was $44 \mathrm{~mm}$. We speculated that there might be 2 reasons for the onset of dysphagia. One reason was the lack of mobility of the tumor. Tumor mobility depends on the size, length of the stalk, and extent of attachment to the heart. Most tumors are pedunculated, with a short, broad base. In unusual circumstances, however, sessile forms may occur. $^{1,4}$ In this patient, despite the large tumor size, the tumor had no mobility because of the sessile forms and therefore caused esophageal compression. The other reason was the location of the esophagus. Lemola and colleagues ${ }^{5}$ reported that the esophagus was close and parallel to the left-sided pulmonary veins in $56 \%$ of patients. In our case, the esophagus was located at the center of the left atrium, so the tumor compressed the esophagus. We consider this to be an unusual case because we found no previous reports of left atrial myxoma presenting with dysphagia.

\section{References}

1. McAllister HA, Fenogolio JJ. Tumors of the cardiovascular system. In: Atlas of tumor pathology, series 2. Washington, DC: Armed Forces Institute of Pathology; 1978.

2. Silverman NA. Primary cardiac tumors. Ann Surg. 1980;191:127-38.

3. Pinede L, Duhaut P, Loire R. Clinical presentation of left atrial cardiac myxoma: a series of 112 consecutive cases. Medicine (Baltimore). 2001;80:159-72.

4. Gopalakrishnaiah GK, Reddy DJ, Rao TS, Sakuntala DP, Suryaprakasa RT, Venkaiah KR, et al. Congenital myxoma of the heart. Indian J Pediatr. 1956;23: 210-2.

5. Lemola K, Sneider M, Desjardins B, Case I, Han J, Good E, et al. Computed tomographic analysis of the anatomy of the left atrium and the esophagus. Circulation. 2004;110:3655-60. 